\title{
Erratum to: Safe application of reclaimed water reuse for agriculture in Korea
}

\author{
Taeil Jang $\cdot$ Sae-Bom Lee $\cdot$ Choung-Hyun Sung $\cdot$ \\ Han-Pil Rhee $\cdot$ Seung-Woo Park
}

Published online: 30 September 2010

(c) Springer-Verlag 2010

Erratum to: Paddy Water Environ (2010) 8:227-233

DOI 10.1007/s10333-010-0203-9

Due to an unfortunate turn of events this article has been published with an erroneous version of one of the authors names and more specific the name of Dr Han-Pil Rhee. Please find below the correct author names listed that should be regarded by the reader as the final version.

Taeil Jang · Sae-Bom Lee · Choung-Hyun Sung . Han-Pil Rhee · Seung-Woo Park

The online version of the original article can be found under doi:10.1007/s10333-010-0203-9.

\section{T. Jang}

Department of Biological \& Agricultural Engineering,

University of Georgia, 2329 Rainwater Road,

Tifton, GA 31793, USA

\section{S.-B. Lee $(\square) \cdot$ H.-P. Rhee}

Department of Environmental Science, Konkuk University,

1 Hwayang-dong, Gwangjin-gu, Seoul 143-701, South Korea

e-mail: saebom@konkuk.ac.kr

C.-H. Sung · S.-W. Park

Department of Rural Systems Engineering,

Seoul National University, 599 Gwanak-ro,

Gwanak-gu, Seoul 151-921, South Korea

T. Jang $\cdot$ S.-W. Park

Research Institute for Agriculture \& Life Sciences,

Seoul National University, 599 Gwanak-ro, Gwanak-gu,

Seoul 151-921, South Korea 